\title{
Isolation of a panel of ultra-potent human antibodies neutralizing SARS-CoV-2 and viral variants of concern
}

Andrey A. Gorchakov' ${ }^{1}$ Sergey V. Kulemzin', Sergey V. Guselnikov ${ }^{1}$, Konstantin O. Baranov' ${ }^{1}$ Tatyana N. Belovezhets ${ }^{1}$, Ludmila V. Mechetina ${ }^{1,2}$, Olga Yu. Volkova', Alexander M. Najakshin', Nikolai A. Chikaev', Anton N. Chikaev', Pavel P. Solodkov', Victor F. Larichev³, Marina A. Gulyaeva (10,4, Alexander G. Markhaev', Yulia V. Kononova4, Alexander Yu. Alekseyev ${ }^{4,5}$, Alexander M. Shestopalov" ${ }^{4,5}$, Gaukhar M. Yusubalieva ${ }^{6}$, Tatiana V. Klypa ${ }^{6}$, Alexander V. Ivanov ${ }^{7}$, Vladimir T. Valuev-Elliston? ${ }^{7}$, Vladimir P. Baklaushev ${ }^{6}$ and Alexander V. Taranin (1) ${ }^{1 凶}$

\begin{abstract}
In the absence of virus-targeting small-molecule drugs approved for the treatment and prevention of COVID-19, broadening the repertoire of potent SARS-CoV-2-neutralizing antibodies represents an important area of research in response to the ongoing pandemic. Systematic analysis of such antibodies and their combinations can be particularly instrumental for identification of candidates that may prove resistant to the emerging viral escape variants. Here, we isolated a panel of 23 RBD-specific human monoclonal antibodies from the B cells of convalescent patients. A surprisingly large proportion of such antibodies displayed potent virus-neutralizing activity both in vitro and in vivo. Four of the isolated nAbs can be categorized as ultrapotent with an apparent $I_{100}$ below $16 \mathrm{ng} / \mathrm{mL}$. We show that individual nAbs as well as dual combinations thereof retain activity against currently circulating SARS-CoV-2 variants of concern (such as B.1.1.7, B.1.351, B.1.617, and C.37), as well as against other viral variants. When used as a prophylactics or therapeutics, these nAbs could potently suppress viral replication and prevent lung pathology in SARS-CoV-2infected hamsters. Our data contribute to the rational development of oligoclonal therapeutic nAb cocktails mitigating the risk of SARS-CoV-2 escape.
\end{abstract}

\section{Introduction}

Virus-neutralizing monoclonal antibodies (nAbs) have invariably been at the forefront of antiviral therapeutic and prophylactic measures due to their excellent safety and efficacy profiles. Since the very beginning of the pandemic caused by SARS-CoV-2, massive research efforts have been focused on the design of vaccines, as well as the development of antiviral molecules and patient-centered therapeutic modalities. Potent protection afforded by the

\footnotetext{
Correspondence: Alexander V. Taranin (taranin@mcb.nsc.ru)

${ }^{1}$ Institute of Molecular and Cellular Biology, Siberian Branch of the Russian

Academy of Sciences, Novosibirsk, Russia

${ }^{2}$ Novosibirsk State University, Novosibirsk, Russia

Full list of author information is available at the end of the article

These authors contributed equally: Andrey A. Gorchakov, Sergey V. Kulemzin,

Sergey V. Guselnikov, Konstantin O. Baranov
}

various vaccine platforms demonstrated in key clinical trials $^{1-4}$ has stimulated global immunization campaigns aiming to prevent COVID-19 and curb the pandemic. Despite this important progress, there is significant need for SARS-CoV-2-neutralizing monoclonal antibodies, as numerous vulnerable categories of individuals either cannot be vaccinated for medical reasons or are unable to mount vaccine-induced protective immune responses. Isolation of SARS-CoV-2-specific nAbs has so far relied on several approaches and included sequencing of individual B cells from convalescent donors or humanized mice ${ }^{5-24}$, SARS survivors ${ }^{25-27}$, as well as screening of antibody, $\mathrm{scFv}$, Fab or VH libraries ${ }^{28-36}$. Hundreds of SARS-CoV-2neutralizing antibodies of different breadth and potency have already been isolated. Currently, dozens of the lead

\section{(c) The Author(s) 2021}

(c) (i) Open Access This article is licensed under a Creative Commons Attribution 4.0 International License, which permits use, sharing, adaptation, distribution and reproduction c. in any medium or format, as long as you give appropriate credit to the original author(s) and the source, provide a link to the Creative Commons license, and indicate if changes were made. The images or other third party material in this article are included in the article's Creative Commons license, unless indicated otherwise in a credit line to the material. If material is not included in the article's Creative Commons license and your intended use is not permitted by statutory regulation or exceeds the permitted use, you will need to obtain permission directly from the copyright holder. To view a copy of this license, visit http://creativecommons.org/licenses/by/4.0/. 
candidates are undergoing clinical trials ${ }^{37}$, and several antibodies or antibody combinations have received either emergency use authorization or were granted approval from the U.S. Food and Drug Administration (FDA). Significant efforts are now centered on the isolation of potent broadly neutralizing monoclonal antibodies that are also active against other sarbecoviruses, and may therefore be effective against possible escape variants of SARS-CoV- $2^{38,39}$. The emergence of SARS-CoV-2 variants of concern (VOCs) has immediately raised the question of the effectiveness of nAbs against these viral variants. Unfortunately, not all monoclonal antibodies capable of neutralizing the ancestral Wuhan or D614G strains are effective against the VOCs. For example, bamlanivimab almost lost its neutralizing activity against the delta variant ${ }^{40}$. Bamlanivimab and etesivimab fail to neutralize the beta variant ${ }^{41}$, whereas the potency of casirivimab is reduced. However, imdevimab remains effective against alpha, beta, and delta $\mathrm{VOCs}^{40,41}$ and sotrovimab retains potency against alpha, beta, and gamma ${ }^{42}$. The efficacy of regdanvimab against the beta variant is significantly reduced, however, in in vivo models, this antibody is still capable of exerting a therapeutic effect ${ }^{43}$. Therefore, isolation and comprehensive characterization of additional SARS-CoV-2-neutralizing monoclonal antibodies continue to be an important area of research, as it opens the opportunity to formulate the cocktails of nAbs that will neutralize or reduce transmission of emerging viral variants that would otherwise escape neutralization by singleantibody preparations.

Here, we isolated a panel of human nAbs specific for SARS-CoV-2 receptor-binding domain (RBD) and characterized their activity in vitro and in vivo. Of these, four nAbs can be classified as ultrapotent. We find that the ACE2 (Angiotensin-Converting Enzyme 2)/RBD interface encompasses a continuum of differentially overlapping epitopes for nAbs that frequently display complimentary profiles of sensitivity to SARS-CoV-2 Spike (S) variants. This informs the rational design of a broader repertoire of RBD-specific cocktails composed of non-competing nAbs that should retain activity against currently circulating viral lineages as well as future variants.

\section{Results}

Selection of convalescent COVID-19 patients with potently neutralizing sera

Two-to-four weeks after the symptom onset, 650 patients with a previously RT-qPCR (Reverse Transcription quantitative Polymerase Chain Reaction)-confirmed SARS-CoV-2 infection were recruited to our study. Blood samples were pre-screened for the presence of RBD-specific antibodies, as these have been demonstrated to correlate with the neutralizing activity of the sera $^{44}$. Consistent with earlier findings on the positive

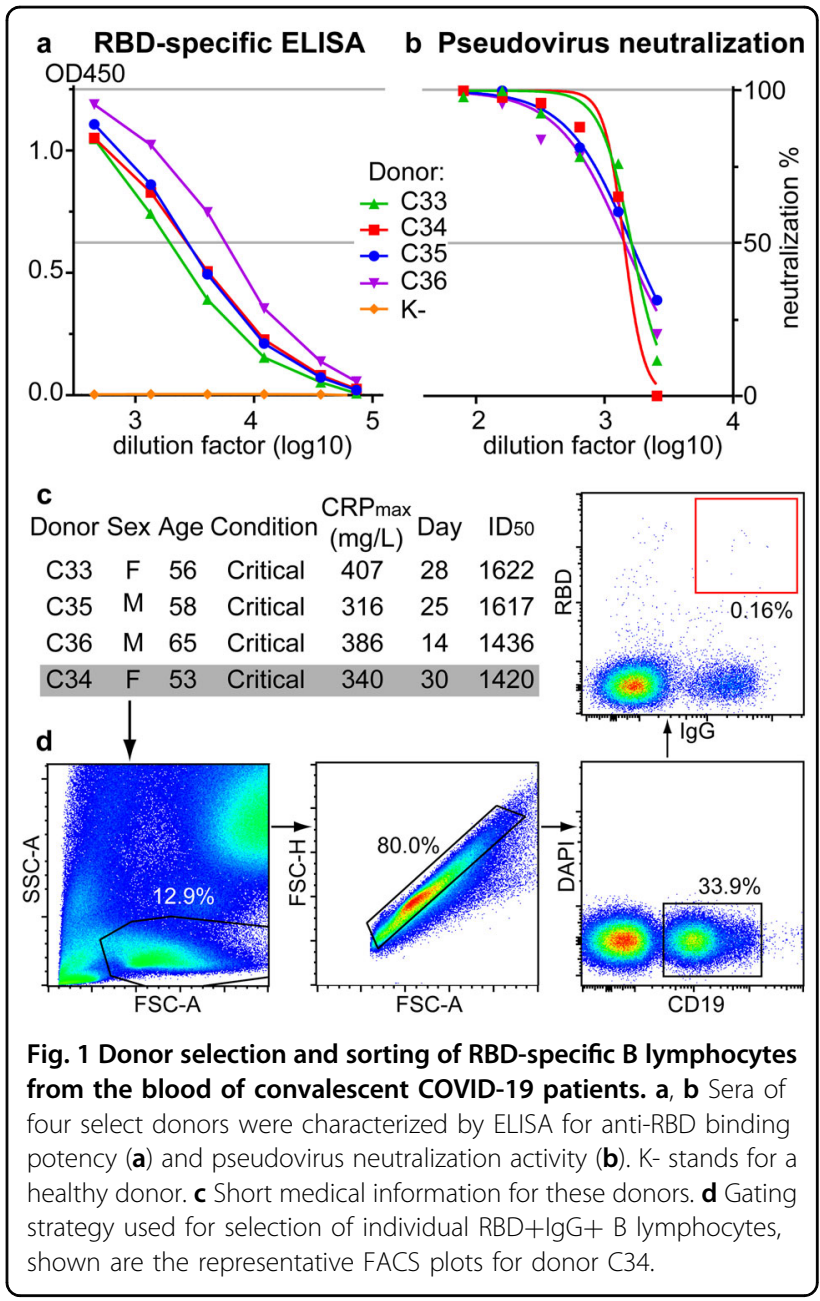

correlation between neutralizing titers and severity of COVID-19 $9^{45,46}$, sera from four critically ill patients displayed particularly high RBD-specific titers $\left(>3.6 \times 10^{4}\right)$ as well as potent pseudovirus-neutralizing activity $\left(\mathrm{ID}_{50}\right.$ range 1420-1622) (Fig. 1a, b). These patients were selected for blood donation (Fig. 1c).

\section{Isolation of RBD-specific human B cells and monoclonal antibodies}

$\mathrm{CD}_{19}{ }^{+} \mathrm{IgG}^{+} \mathrm{B}$ cells were isolated from peripheral blood samples and stained using a biotinylated SARS-CoV-2 RBD. To set a stringent gating threshold, B cells from a healthy donor were used as a control. The frequency of $\mathrm{CD}_{19}{ }^{+} \mathrm{IgG}^{+} \mathrm{RBD}^{+} \mathrm{B}$ cells in patients $\mathrm{C} 33, \mathrm{C} 34, \mathrm{C} 35$, and C36 varied from 0.032 to $0.091 \%$ (Supplementary Table S1). Only RBD ${ }^{\text {high }} \mathrm{B}$ cells were flow-sorted into individual tubes (Fig. 1d). Seventy-two individual B cells were flowsorted, half of which (40) were from patient C34.

Next, pairs of expressed VH- and VL-gene sequences were successfully retrieved for $33 \mathrm{~B}$ cells $(1,3,4$, and $25 \mathrm{~B}$ cells from patients C36, C33, C35, and C34, respectively). 
Of these, 28 had unique combinations of $\mathrm{VH}$ and $\mathrm{VL}$ sequences. Twenty-five of these sequences were observed in only one cell each, whereas the remaining eight were found across the clones composed of 2 or 3 cells each (iB1, iB2, and iB8). Thus, 28 recombinant IgG1-class antibodies were produced in HEK293T cells and purified via Protein A chromatography. Of these, 23 antibodies turned out to be specific for RBD, as assayed by ELISA (Enzyme-Linked Immunosorbent Assay) (iB7, iB8, iB22, iB23, and iB27 were not followed up, as they lacked appreciable binding to RBD). BLI (Bio-Layer Interferometry) analysis indicated that only two RBDspecific antibodies, $\mathrm{iB} 1$ and $\mathrm{iB} 2$, were low-affinity $(K \mathrm{D}=$ 1.0 and $1.5 \mu \mathrm{M}$, respectively) and three were in the moderate affinity subgroup (iB3 $78 \mathrm{nM}, \mathrm{iB} 431 \mathrm{nM}, \mathrm{iB} 10$ $106 \mathrm{nM})$. In total, 18 high-affinity RBD-specific antibodies were obtained with a $K \mathrm{D}$ ranging from 0.47 to $13.3 \mathrm{nM}$ (Fig. 2; Supplementary Fig. S1 and Table S2). We asked whether the above 23 RBD-specific antibodies were reactive towards RBD in the native context of the SARS-CoV-2 S protein. To address this question, FACS (Fluorescence-Activated Cell Sorting) analysis of HEK293T cells expressing SARS-CoV-2 S ptotein on their surface was performed. All the 23 antibodies stained S-expressing HEK293T cells, though the intensity of staining varied broadly (Fig. 2). Notably, none of the antibodies recognized the $\mathrm{S}$ proteins from two distantly related alphacoronaviruses, $\mathrm{HCoV}-229 \mathrm{E}$ and HCoV-NL63 (Supplementary Fig. S2), consistent with high degree of sequence divergence of their RBDs and the B cell selection strategy.

In light of the possible therapeutic application, we wished to explore the possibility that the antibodies isolated could be autoreactive, i.e., recognize human self-antigens, as this has previously been reported for a number of SARS-CoV-2-specific antibodies isolated from COVID-19 patients ${ }^{19,20}$. Autoreactivity potential was assessed using a FACS-based HEp-2 immunostaining assay, where only three antibodies (iB0, iB11, and iB21) were scored positive (Fig. 2). None of these have subsequently been shown to possess neutralizing activity (see below).

\section{Identification of human monoclonal antibodies displaying virus-neutralizing activity}

Although several mechanisms of SARS-CoV-2 neutralization by monoclonal antibodies have been described, most of the RBD-specific antibodies do so by disrupting the interaction between RBD and ACE2, the major entry receptor of the virus. Sixteen of the antibodies in our panel were capable of efficiently blocking the interaction between soluble biotinylated SARS-CoV-2 RBD and ACE2 that was ectopically expressed on the surface of HEK293T cells. In this FACS assay, which served as a simple surrogate for

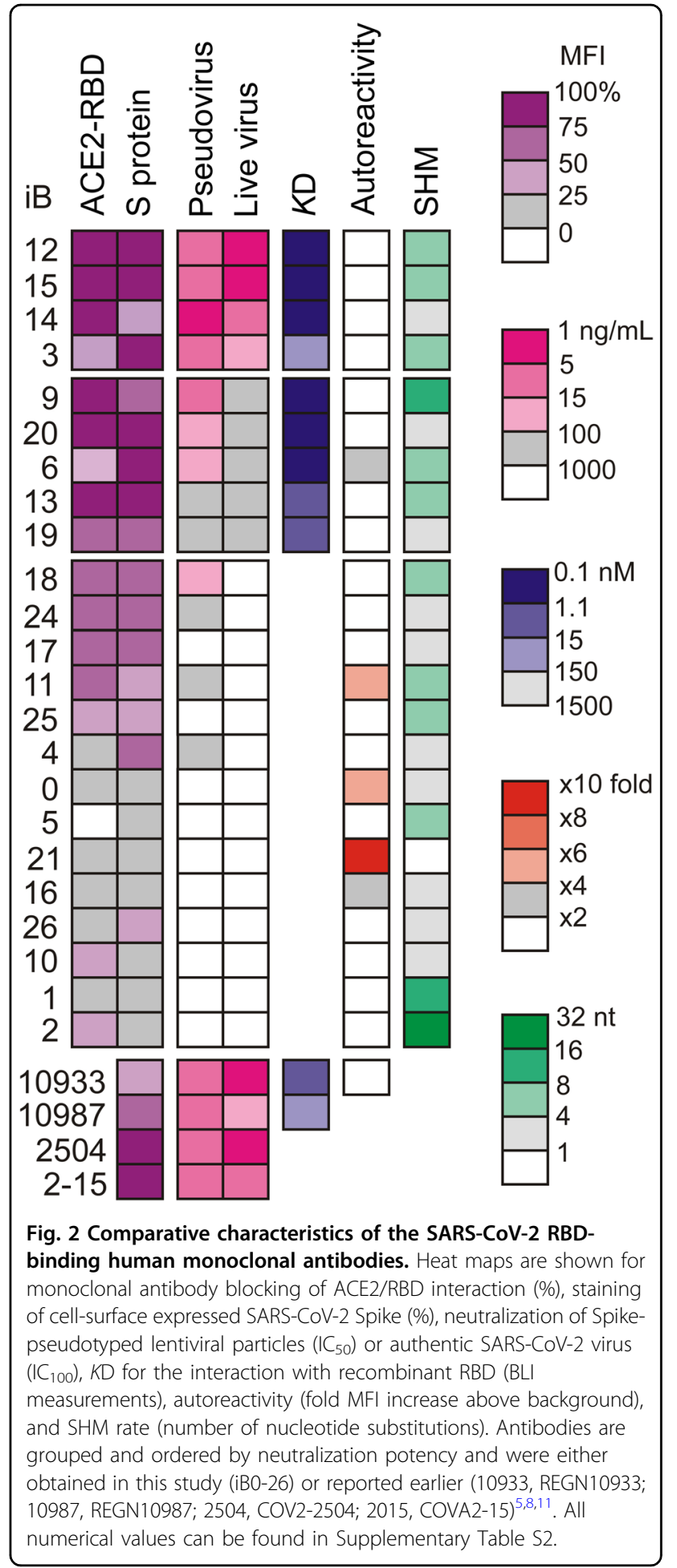

virus-neutralization test, nine antibodies were shown to potently block ACE2/RBD interaction (> 75\% MFI (mean fluorescence intensity) reduction) (Fig. 2).

Next, we carried out an analysis of virus neutralization using S-pseudotyped lentiviral particles and ACE2HEK293T cells as the targets. At the cut-off threshold 


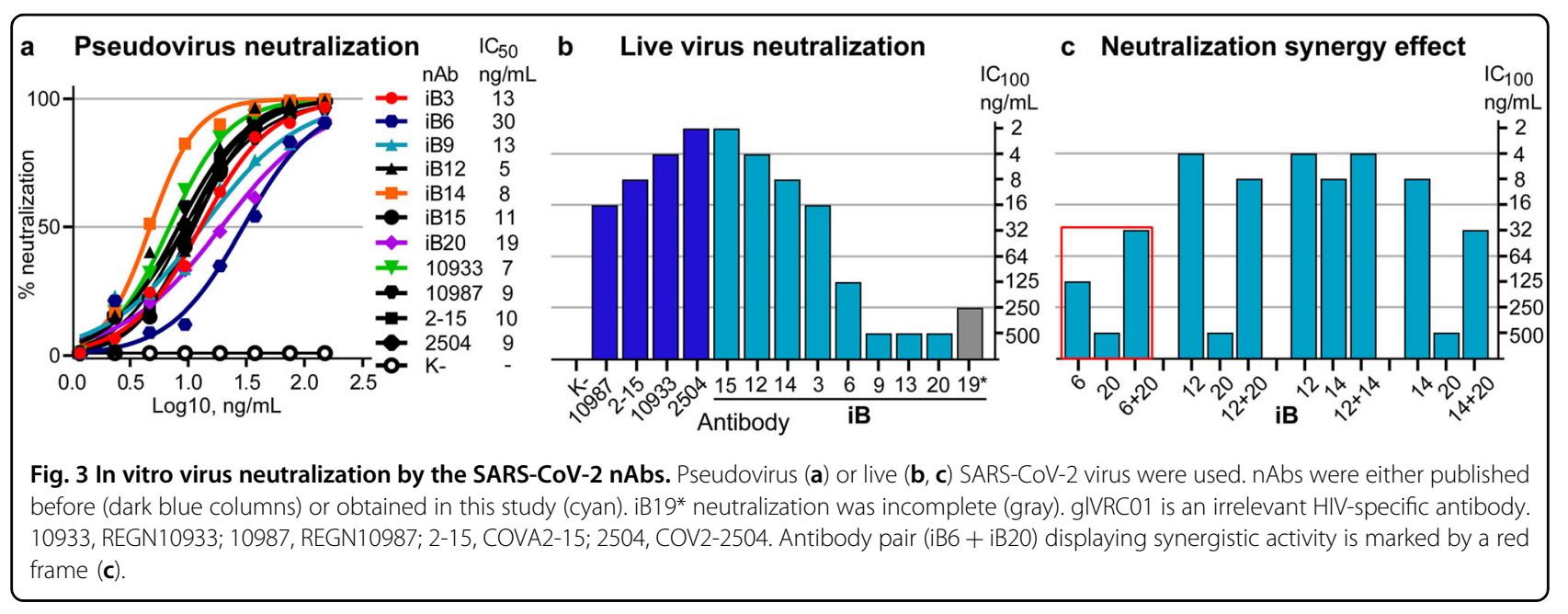

of $\mathrm{IC}_{50}$ below $1 \mu \mathrm{g} / \mathrm{mL}, 13$ antibodies demonstrated virusneutralizing activity (Fig. 2; Supplementary Table S2), of which 7 most promising nAbs were identified as neutralizing at $\mathrm{IC}_{50}$ below $0.03 \mu \mathrm{g} / \mathrm{mL}$ (Fig. 3a).

In order to understand whether the antibodies were active towards the authentic SARS-CoV-2, virus neutralization assays were performed using authentic SARSCoV-2 and VeroE6a cells (Fig. 3b; Supplementary Table S2). Neutralization activity was indeed confirmed, and four of the leading $\mathrm{nAb}$ candidates-iB15, iB12, iB14, and iB3-were considered ultrapotent (arbitrary cut-off threshold of $\mathrm{IC}_{100} \leq 16 \mathrm{ng} / \mathrm{mL}$ ). Accordingly, our BLI analysis showed that except for $\mathrm{iB} 3(\mathrm{KD}=77.8 \mathrm{nM})$ all of these nAbs had high affinity to RBD with a $K D$ ranging from 0.47 to $1.09 \mathrm{nM}$ (Fig. 2; Supplementary Fig. S1 and Table S2). To explore whether synergy between iB-series nAbs may exist, various antibody combinations were tested in live virus neutralization assay. Of these, only the cocktail made of nAbs iB6 and iB20 targeting nonoverlapping epitopes (see below) was shown to display detectable synergy (Fig. 3c).

\section{SARS-CoV-2-neutralizing antibodies perform on par with the published top neutralizing antibodies}

Neutralization assays performed by different groups may suffer inconsistencies due to minor details in virus production, handling, and assay readout. To avoid these possible pitfalls we decided to compare the antibodies in the same setting. Specifically, we asked whether the antibodies isolated in our work would display neutralization activities that compare well to the four of the most potent RBD-specific antibodies, two of which have already advanced to clinical use. To this end, we produced highly potent SARS-CoV-2-neutralizing antibodies REGN10933 (casirivimab), REGN10897 (imdevimab) ${ }^{8}$, COVA2-15 ${ }^{5}$, and COV2-2504 $4^{47}$. In our hands, these antibodies displayed an $\mathrm{IC}_{50}$ of $7,9,10$, and $9 \mathrm{ng} / \mathrm{mL}$ against the
S-pseudotyped lentivirus (Fig. 3a), and $\mathrm{IC}_{100}$ of 4, 16, 8, and $2 \mathrm{ng} / \mathrm{mL}$ against the authentic SARS-CoV-2, respectively (Fig. 3b). These numbers are in line with the published values, and minor differences are likely attributable to the differences in assay set-up. Thus, the lead four monoclonal antibodies obtained in our work display neutralization potency in the range of the best SARS-CoV2-neutralizing RBD-specific antibodies published to date.

\section{The isolated RBD-specific SARS-CoV-2-neutralizing antibodies belong to public clonotypes}

Previously, significant diversity of genes encoding RBDspecific SARS-CoV-2-neutralizing antibodies has been reported, with extensive enrichment in antibodies having nearly germline configuration ${ }^{5,19,48}$. We observed a similar trend, as representatives of $10 \mathrm{VH}$ - and $7 \mathrm{VL}$ - gene segments were present among the antibody-encoding genes (Supplementary Figs. S3, S4 and Table S3). Consistent with the previous findings on the enrichment of particular classes of RBD-specific nAbs, several VH genes, such as VH3-53 (iB18, iB20, iB24, iB25), VH1-2 (iB3, iB12), VH1-69 (iB6, iB9), VH1-58 (iB14), and VH3-66 (iB19) were present in our panel. Notably, VH3-53/66derived nAbs have short (11-13 residues) CDRH3s (Heavy chain Complementarity Determining Regions 3 ) and may be attributed to the recurrent class I antibodies known to bind a common epitope in "up" RBD conformation ${ }^{49,50}$. VH1-58/VK3-20-encoded iB14 appears to belong to another public clonotype that binds to convex tip of $\mathrm{RBD}^{51}$, COV2-2196 ${ }^{11}$, and $2 \mathrm{C}^{2} 8^{52}$.

We next turned to the analysis of SHM (Somatic Hypermutation) levels in our antibodies, and only two of these, iB1 and iB2, were encoded by the VH genes displaying high SHM rate (8-10 aa). Notably, these two antibodies had the lowest affinity to RBD and lacked neutralizing activity (Fig. 2; Supplementary Table S3). Four antibodies were derived from nearly germline $\mathrm{VH}$ 
sequences (no amino acid changes). One of these, iB21 showed the highest autoreactivity score (Fig. 2). The remaining antibodies had 1-4 aa substitutions. It was this subgroup of antibodies that had pronounced neutralizing activity in our assays. We asked whether neutralization was in any way related to the antibody affinity to RBD, CDR3L/CDR3H length, or other quantitative features measured in our experiments, and observed that only the MFI of S-expressing cell staining and ability to block the ACE2/RBD interaction were significantly correlated with the neutralization potency (Supplementary Fig. S5).

BLI competition analysis defines a continuum of partially overlapping antibody epitopes in the RBD-ACE2 interface

We turned to BLI measurements of cross-competition between 22 RBD-specific antibodies for binding to RBD. In these experiments, RBD was immobilized to the sensor and then saturated by the first antibody. The pre-formed RBDAb1 complex was then exposed to a competing Ab2. Most of the nAbs fell into one of the two distinct clusters (Supplementary Fig. S6). Cluster I encompassed highly potent antibodies iB3, iB12, iB14, and iB15, as well as moderately potent $\mathrm{iB} 13$ and weakly potent $\mathrm{iB} 11$. Cluster II was formed by the moderately and weakly potent iB9, iB17, iB18, iB19, iB20, iB24, and iB25. One more neutralizing antibody, iB6, branched distinctly. Non-neutralizing antibodies clustered separately from the nAbs.

In order to understand whether the antibodies isolated in our study could be combined together as well as with several published nAbs to form cocktails, we proceeded to compare the epitope specificity of our 9 leading candidates with REGN10933, REGN10987, COVA2-15, and COV2-2504 ${ }^{5,8,11}$. REGN10933 and REGN10987 are known to recognize non-overlapping epitopes on RBD, with the epitope of the former antibody found directly at the ACE2/RBD interface, and the epitope of the latter antibody found at the edge. The structures of COVA2-15 and COV2-2504 epitopes have not been determined with high resolution. Yet, it is known that both antibodies compete with ACE2 for binding to RBD and that COVA2-15 interacts with RBD in both "up" and "down" conformations ${ }^{5}$.

Our BLI experiments showed that iB20, iB6, and REGN10987 can bind simultaneously to RBD, indicating that the $\mathrm{ACE} 2 / \mathrm{RBD}$-interface region encompasses three distinct, non-overlapping epitopes (Fig. 4a). The rest of the nAbs recognize a continuum of epitopes that display various degrees of overlap with the above three epitopes (Fig. 4b; Supplementary Figs. S6 and S7). For instance, the antibodies iB3, iB12, iB13, iB14, iB15, REGN10933, and COV2-2504 fully compete with each other but show different competition patterns when tested against COVA2-15 and REGN10987. The latter pair competes with iB3 and iB12 but not with iB13 and
iB14. Three other antibodies, REGN10933, iB15, and COV2-2504, do not compete with REGN10987 but strongly compete with COVA2-15. Antibodies iB3, iB12, iB13, iB14, iB15, REGN10933, COV2-2504, and COVA215 , when pre-bound to RBD, ablate binding of the iB9, iB19, and iB20. Yet, in the reverse set-up of the assay, the blocking was incomplete. To summarize, our competition analysis so far is consistent with the clustering of the 13 nAbs tested into 8 epitope specificity groups: iB13/iB14, REGN10933/COV2-2504/iB15, iB3/iB12, iB9, COVA215, iB19/iB20, iB6, and REGN10987 (Fig. 4b). Interestingly, this continuum of epitopes provides multiple opportunities to formulate cocktails of noncompeting nAbs. Even in our limited panel of the tested nAbs, seven such cocktails may be designed in addition to the clinicalstage combination REGN10933 + REGN10987. These include iB14 + COVA2-15, iB14 + REGN10987, iB20 + iB6, iB15 + REGN10987, COV2-2504 + REGN10987, iB20 + REGN10987, and finally a tripartite cocktail iB6 + iB20 + REGN10987.

\section{Both published and newly identified nAbs differ in their sensitivity to select SARS-CoV-2 mutations, including those present in the VOCs}

SARS-CoV-2 is known to accumulate genetic changes throughout the pandemic, and so far the mutation rate has been relatively low. However, the emergence of viral lineages resistant to the monoclonal antibodies or polyclonal sera has already been reported and is of great concern. To explore whether iB-series antibodies are sensitive to the RBD mutations, we established a panel of 9 variants of $S$ protein, each carrying a distinct singleamino acid substitution in RBD (K417N, N439K, K444Q, N460T, A475V, E484K, F486K, F490L, and N501Y) and tested it in pseudovirus neutralization assay against seven nAbs (iB3, iB6, iB9, iB12, iB14, iB15, and iB20) and four benchmark nAbs (REGN10987, REGN10933, COVA2-15, COV2-2504). Notably, N501Y substitution is present in the RBD of several viral VOCs, namely in the 501Y.V1 (B.1.1.7 lineage), 501Y.V2 (B.1.351 lineage), and 501Y.V3 (P.1 lineage). In the latter two, N501Y is found in combination with $\mathrm{K} 417 \mathrm{~N}$ and $\mathrm{E} 484 \mathrm{~K}$. The E484K mutation was also found in the spreading B.1.525 lineage and was demonstrated to ablate the activity of a number of nAbs ${ }^{7,8,49,53-56}$.

Our data indicate that of these $\mathrm{S}$ variants, three mutations, namely E484K, F486K, and F490L had the most pronounced effect on the neutralizing ability of nAbs (Fig. 5a), which is in agreement with above studies. Specifically, the E484K $S$ variant was completely resistant to 7 out of the 11 nAbs tested. Three nAbs, iB14, iB20, and REGN10987, were not affected, whereas REGN10933 was 11-fold less potent against this mutant. F490L fully abrogated neutralization by $\mathrm{iB} 12$ and $\mathrm{iB} 15$. This variant 

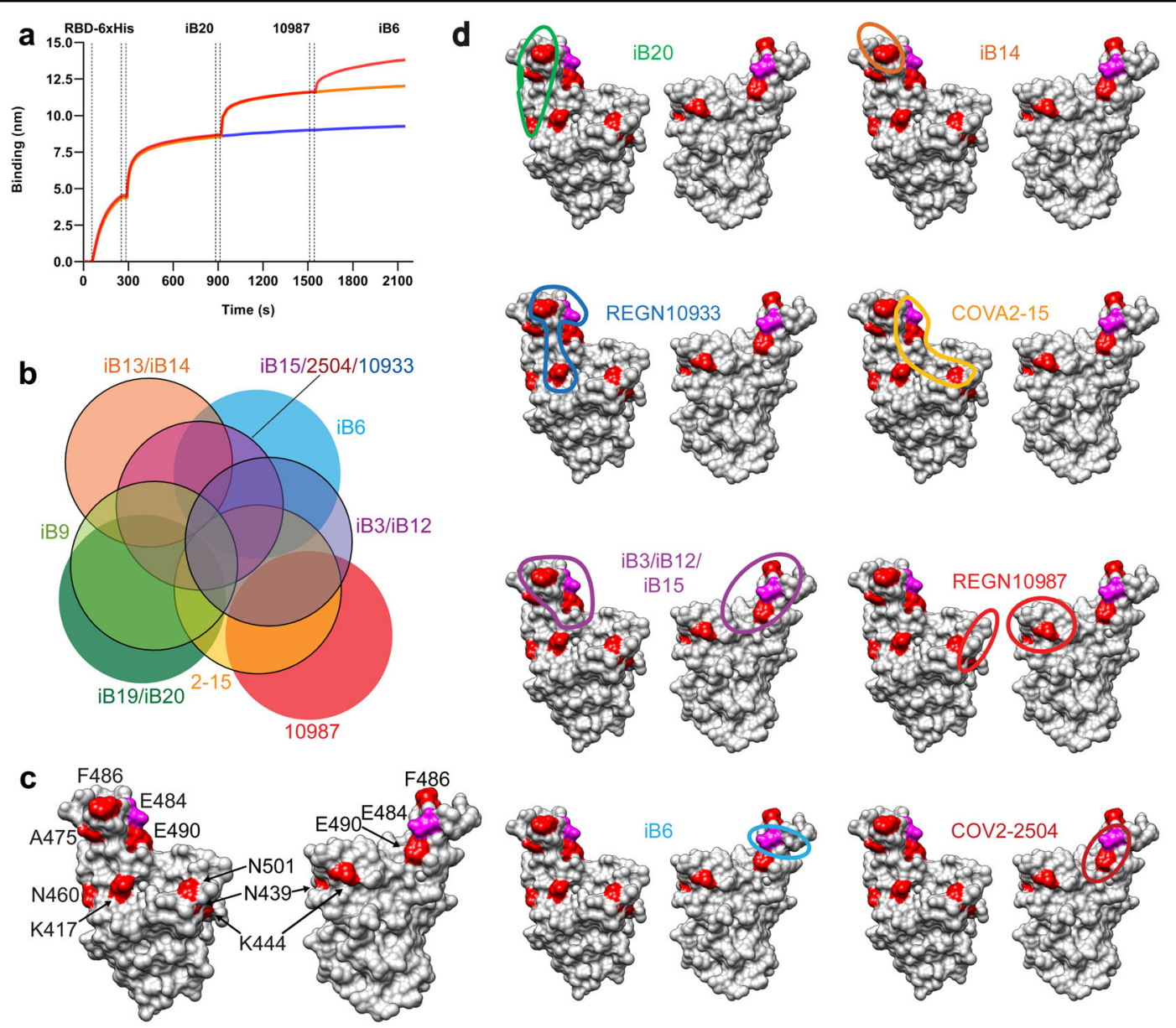

Fig. 4 Epitope binning of SARS-CoV-2 RBD-specific nAbs. The analysis includes either previously published (REGN10987, REGN10933, COVA2-15) or iB-series of nAbs. a BLI analysis of competition between nAbs iB20, REGN10987, and iB6 for RBD binding. $\mathbf{b}$ Venn diagram showing mutual overlap between the tentative epitopes of nAbs forming eight distinct bins. The diagram was plotted based on the BLI data (Supplementary Figs. S6 and S7). c Positions of nine mutations escaping neutralization by at least one of the tested antibodies. Residues mutated are highlighted red or pink on the 3D model of SARS-CoV-2 RBD. $\mathbf{d}$ Tentative positions of nAb footprints are circled.

reduced virus-neutralizing activity of $\mathrm{iB} 3$ and COV2-2504 by 20 fold, whereas iB9, iB20, and COVA2-15 were only marginally affected. Activity of iB20 was strongly attenuated by $\mathrm{N} 460 \mathrm{~T}$ and A475V. Consistent with the published data, K417N substitution reduced the neutralizing activity of REGN10933, whereas N439K and K444Q affected REGN10987 $7^{54,55}$. None of the latter three mutations appreciably affected any of the iB-series of nAbs. COVA2-15 was the only nAb in this panel that was somewhat sensitive to the N501Y S variant, which is in line with the recent findings ${ }^{57}$.

To refine the interplay between the epitopes recognized by nAbs isolated in our study as well as by the reference nAbs, the positions of the tested RBD substitutions were placed on the 3D structure of RBD $(7 \mathrm{CH} 5)^{58}$ (Fig. 4c, d). As expected, the key residues important for neutralization by each antibody clustered together. This clustering matches very well both the known epitope positions for
REGN10933 and REGN10987 ${ }^{5,8}$ and the Venn diagram based on our competition data (Fig. $4 \mathrm{~b}$ ). Thus, the escape mutation patterns observed further substantiate the design of seven competition-based nAb cocktails proposed above.

Next, we asked whether our lead nAbs iB14 and iB20 would be active against lentiviral particles pseudotyped with the triple-mutant $\mathrm{S}$ carrying the substitutions at key residues K417, E484, and N501 (KEN), given that this mutant combination is present in the RBD of two viral VOCs, 501Y.V2 and 501Y.V3. In line with the inability of individual $\mathrm{S}$ mutants to confer resistance to iB14 and iB20, as well as to the reference nAb REGN10987, these three $n A b s$ were found to retain full neutralizing activity, unlike iB6 and COVA2-15, whose activity was abolished (Fig. 5b). As expected, the cocktails of iB6 with iB20 or REGN10987, as well as of COVA2-15 with iB14 were fully efficient in neutralizing the KEN variant (Supplementary Fig. S8). 


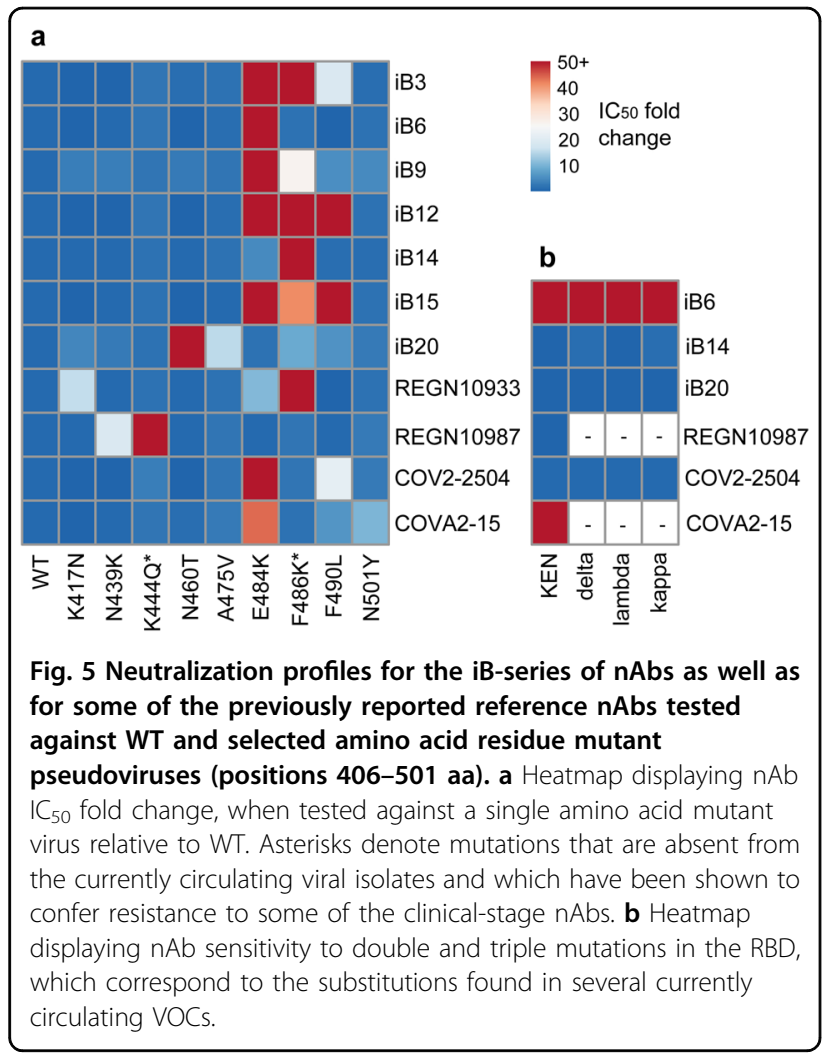

Finally, to extend our studies, we assessed the ability of iB6, iB14, and iB20 to neutralize lentiviral particles pseudotyped with $S$ variants each carrying two RBD substitutions found in the delta (B.1.617.2 (L452R + T478K)), kappa (B.1.617.1 (L452R + E484Q)), and lambda (C.37 (L452Q + F490S)) viral lineages that have appeared in circulation very recently. nAbs iB14 and iB20 retain full neutralization potency against these variants (Fig. 5b) unlike iB6, which appears sensitive to the substitutions at L452 residue shared between the above mutant $\mathrm{S}$ proteins. Taken together, these results point to the possible utility of iB14 and iB20 for therapeutic use in patients infected with such SARS-CoV-2 variants.

\section{iB-series of antibodies display potent in vivo activity}

Whether the in vitro virus-neutralizing activity of iBseries antibodies translates into in vivo activity was unknown, and we proceeded to test this in a Syrian hamster infection model. Specifically, we first selected iB12 and a 1:1 mixture of iB6/B20 to be used as a prophylactics and/ or therapeutics of SARS-CoV-2 infection and pathology in hamsters (Fig. 6, Experiment 1). After the completion of this experiment, several SARS-CoV-2 VOCs had emerged, which were predicted to be resistant to iB12 in our above analysis, so we conducted an additional in vivo experiment with the iB14 antibody exhibiting a favorable profile of sensitivity to the viral variants (Fig. 6, Experiment 2).
Both prophylactic and therapeutic regimens were clearly efficacious. Whereas control animals lost up to $15 \%$ of their weight by 5 dpi (day post infection), all the animals from experimental groups gained weight from 3 dpi (Fig. 6a). Quantification of viral RNA in lung tissue homogenates indicated that hamsters who were given the neutralizing antibodies prophylactically had overall 2-6 orders of magnitude lower levels of viral RNA, compared to the controls. Notably, therapy of the infected hamsters with $\mathrm{iB} 12$ or $\mathrm{iB} 14$ at the dose of $1 \mathrm{mg}$ was also protective, as viral load was dramatically reduced (Fig. 6b). In the control animals, in addition to the high viral load, all the signs of interstitial pneumonia were found, including massive peribronchial and perivascular leucocyte infiltration accompanied by edema, multifocal necrosis in interstitium and significant pulmonary consolidation that affected more than $50 \%$ of the lung. Prophylactic administration of iB12 $(1 \mathrm{mg})$ had the strongest protective effect in the lungs, as only minimal lung damage was found in this group. Lower dose of iB12 $(0.1 \mathrm{mg})$, the $\mathrm{iB6}+\mathrm{iB} 20$ mix $(0.1$ and $1 \mathrm{mg})$ as well as the therapeutic injection of iB12 prevented the development of pneumonia, although thickened alveolar septae with mild type II alveolar epithelial cell hyperplasia or desquamated epithelium in the bronchiolar lumena and perivascular cuffing were occasionally observed (Fig. 6c; Supplementary Fig. S9). Therapy with a low dose of iB14 or delayed administration of iB14 did not appreciably reduce viral RNA concentration in hamster lungs, although the weight loss was significantly lower.

\section{Discussion}

Mounting evidence suggests that emerging viral variants tend to display resistance to neutralization not only to current clinical-stage monoclonal antibodies, but also to sera from convalescent patients and immunized donors $^{54,59-62}$. Here, we used single B cell sorting from four severely ill COVID-19 patients who got infected early in the course of the pandemic to isolate human SARS$\mathrm{CoV}-2$-specific nAbs. In total, a panel of 23 antibodies was obtained, of which 13 were virus-neutralizing and 4 could be classified as ultrapotent. We focused on seven lead candidates (iB3, iB6, iB9, iB12, iB14, iB15, iB20) to explore their ability to neutralize several viral variants. Notably, both naturally occurring and synthetic mutants absent from the circulation were included in our analysis, as these have been demonstrated to escape neutralization by one or more clinical-stage $\mathrm{nAbs}^{59,63}$. Our data indicate that while each of the nAbs tested was ineffective against at least one of the $S$ mutants, none of the mutations ablated the activity of the entire panel of nAbs. Next, based on the sensitivity profiles of the lead nAbs, we narrowed the selection of candidates to neutralize the "worst case scenario" viral VOC, B.1.351 defined by 


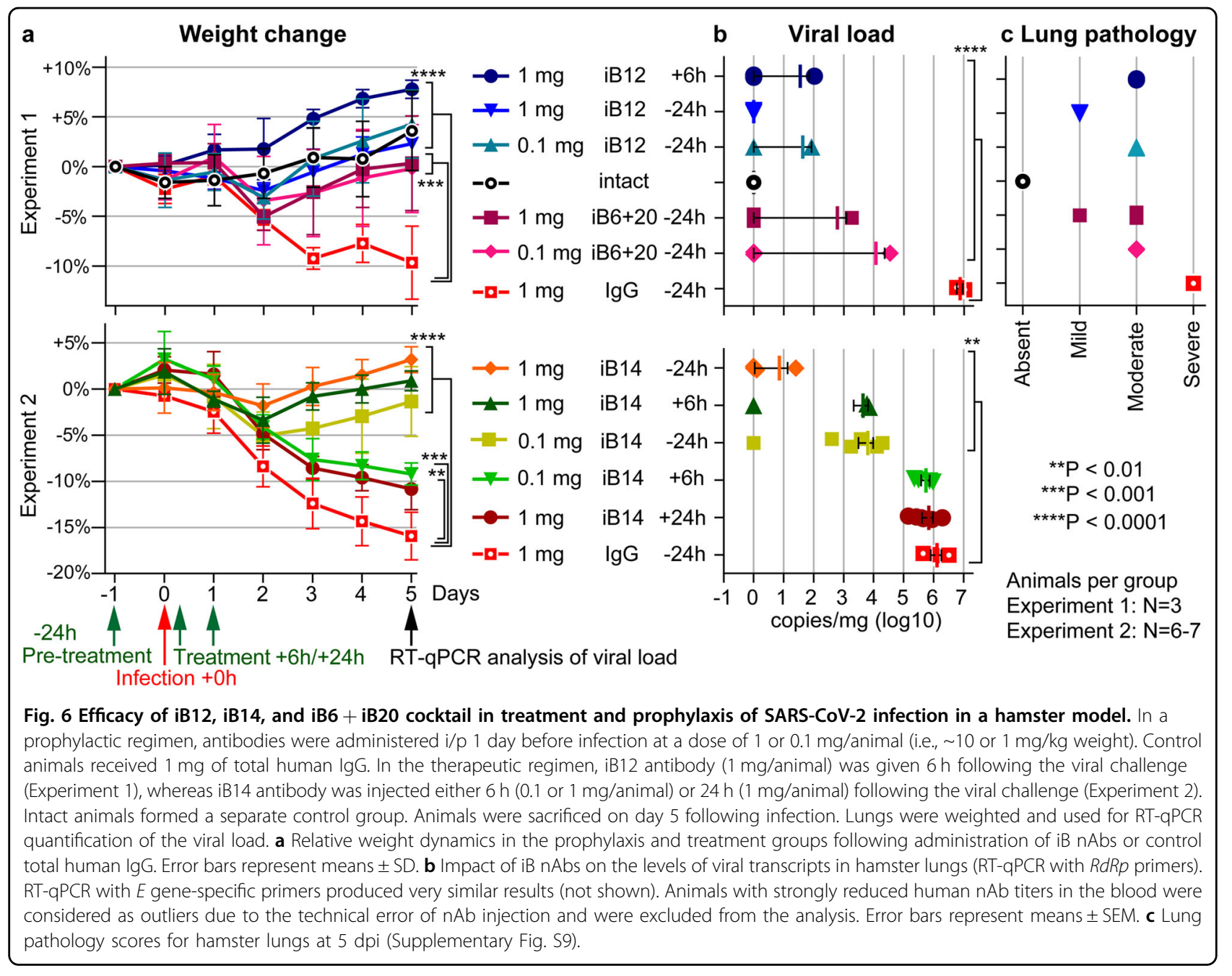

the triple substitution (KEN) within the RBD. In this analysis, two nAbs, iB14 and iB20 were found to retain full neutralizing activity, consistent with the failure of singleamino acid S mutants $\mathrm{K} 417 \mathrm{~N}, \mathrm{E} 484 \mathrm{~K}$, and N501Y to confer resistance to these nAbs. Of relevance, iB14 and iB20 were also found to be fully active against pseudotyped lentiviral particles with RBD substitutions in the Spike corresponding to the delta, kappa, and lambda viral lineages. Interestingly, one more residue, F486, has been reported to be critical for binding of several potent nAbs, including the clinical-stage REGN10933, LY-CoV555, and LY-CoV016 $6^{54,55,63}$. In our panel, iB6 could fully neutralize the mutant pseudovirus bearing the F486K substitution. Thus, from the practical standpoint, our panel encompasses three nAbs-iB6, iB14, and iB20 that complement the repertoire of the published nAbs in terms of activity against the most pressing $\mathrm{S}$ mutations.

Therefore, based on these nAbs, one can envisage the design of two therapeutic cocktails such as $\mathrm{iB} 6+\mathrm{iB} 20$ and iB6 + iB14. Importantly, iB6 and iB20, unlike iB6 and
iB14, do not compete for binding to $\mathrm{S}$ protein, i.e., they recognize non-overlapping epitopes, and this cocktail $(\mathrm{iB6}+\mathrm{iB20})$ represents an optimal combination as it should provide a broader neutralization coverage of the emerging and future viral variants. To analyze whether the cocktail composed of iB6 and iB20 performs well in vivo as a prophylactic agent, we had it tested in a hamster infection model, and confirmed that this was indeed the case.

Yet, another important feature that may affect clinical performance of the antiviral nAbs is their potency, as it could translate into reduced dosage and manufacturing costs $^{64}$. We turned to one of the most potent nAbs in our panel, iB12, to test it as both prophylactic and therapeutic agent in hamsters, even though it is sensitive to substitutions at key E484, F486 and F490 residues of the Spike. When faced against the D614G-bearing isolate of SARS-CoV-2, iB12 was fully functional and suppressed both viral replication and lung pathology in the infected animals. 
From a broader perspective, our data on the resistance to viral escape mutations and epitope binning open an exciting opportunity to formulate nAb cocktails with a number of clinical-stage nAbs. For instance, iB6 and iB20 could be combined with REGN10987 to form a tripartite cocktail composed of entirely non-overlapping nAbs targeting the ACE2/RBD interface. Other interesting combinations are also possible, such as iB14 + COVA2-15 or iB14 + COV2-2504, offering the advantage of a broader antibody footprint and lower risk of mutation escape.

There are also some limitations of this study. Syrian hamster model of SARS-CoV-2 infection used in this work does not fully address the complexity of COVID-19 in humans. Only clinical trials will be informative regarding the efficacy and safety of the panel of nAbs obtained in our work in the context of COVID-19 prophylaxis and therapy. To test for viral escape from neutralization by the nAbs, S-pseudotyped lentiviral particles were used, therefore these data may need validation using authentic SARS-CoV-2 viral variants. We did not test the $\mathrm{nAb}$ stability or half-life in the bloodstream-the parameters that are critical for subsequent drug development.

Given that nAbs tested in our study were screened against SARS-CoV-2 RBD and were exclusively RBDspecific, we constructed $S$ protein variants corresponding to the viral VOC by incorporating only the mutations found within the RBD, although these variants do contain additional substitutions in the $\mathrm{N}$-terminal domain and $\mathrm{S} 2$ regions of the Spike.

\section{Materials and methods}

\section{Convalescent donor samples}

Peripheral blood samples were collected from more than 650 convalescent donors with a laboratoryconfirmed COVID-19 (commercial RT-qPCR tests and/ or specific pattern of polysegmental viral pneumonia with areas of "ground glass" opacity on high-resolution computed tomography) who were treated at the FRSC FMBA of Russia (Moscow). De-identified heat-inactivated serum samples displaying anti-RBD Spike IgG titers (SARS-CoV2-IgG-IFA test, Xema Ltd, Russia) 1:5000 or higher were selected for further analyses. Specifically, 12 serum samples were prioritized for RBD-specific ELISA (see below), of which fresh peripheral blood samples were immediately available for four patients. Control samples were obtained from healthy individuals without any history of SARSCoV-2 infection.

\section{Expression and purification of SARS-CoV-2 RBD-His6 antigen}

A plasmid pCAAGS-mRBD-His6 encoding a His-tagged RBD of SARS-CoV-2 S protein was a kind gift of Prof. Florian Krammer ${ }^{65}$. HEK293T cells were cultured in DMEM supplemented with 10\% FBS and $2 \mathrm{mM}$ glutamine at $37^{\circ} \mathrm{C}$ in $5 \% \mathrm{CO}_{2}$. For transfection, they were seeded onto four $100 \mathrm{~mm}$ dishes at $70 \%$ density, and $18 \mathrm{~h}$ later transfected with $12 \mu \mathrm{g} /$ dish of the plasmid pCAAGmRBD-His6 premixed with $24 \mu \mathrm{L} /$ dish of the Lipofectamine 3000 reagent (Invitrogen) according to the manufacturer's instruction. Twenty-four hours later the cells were harvested with trypsin-EDTA, resuspended in a fresh DMEM medium supplemented with $10 \%$ FBS, $2 \mathrm{mM}$ glutamine, and $20 \mathrm{mM}$ HEPES, $\mathrm{pH}$ 7.2, and seeded onto $850 \mathrm{~cm}^{2}$ roller dish (Corning). Three days later the medium was collected and applied on a $1 \times 3 \mathrm{~cm} \mathrm{Ni-NTA-}$ agarose column (Novagen). The resin was washed with $25 \mathrm{~mL}$ of wash buffer ( $25 \mathrm{mM}$ Tris-HCl, pH 7.5, $500 \mathrm{mM}$ $\mathrm{NaCl}, 10 \%(\mathrm{v} / \mathrm{v})$ glycerol, and $1 \mathrm{mM}$ 2-mercaptoethanol), and three more times with a wash buffer supplemented with 10,30 , and $50 \mathrm{mM}$ imidazole $(20 \mathrm{~mL}$ each). The protein was eluted with the buffer containing $250 \mathrm{mM}$ imidazole. Protein concentration in the fractions was estimated by Bradford reagent, and the fractions with the highest concentrations were combined and dialyzed either against PBS (Phosphate Buffer Saline) for immediate use or against a buffer containing $25 \mathrm{mM}$ Tris- $\mathrm{HCl}, \mathrm{pH} 7.5$, $10 \%$ glycerol, and $250 \mathrm{mM} \mathrm{NaCl}$, followed by the same buffer with $50 \%$ glycerol, and stored at $-20{ }^{\circ} \mathrm{C}$.

\section{RBD biotinylation}

RBD-His6 (1 mL, $1 \mathrm{mg} / \mathrm{mL}$ in PBS) was reacted with $10 \mu \mathrm{L}$ Biotin-X-X-NHS $(10 \mathrm{mg} / \mathrm{mL}$ in DMF) (Merck) for $1 \mathrm{~h}$ at room temperature. Once the reaction was complete, the excess of biotin was removed by dialysis against PBS.

\section{ELISA-based detection of SARS-CoV-2 RBD-specific lgGs in human sera}

The antigen (RBD-His6) was diluted in PBS to a final concentration of $0.8 \mu \mathrm{g} / \mathrm{ml}$, and $50 \mu \mathrm{L}$ of this solution was applied to each well of a high binding capacity 96-well plate from Costar (Corning ${ }^{\circledR} 96$ Well EIA/RIA Assay Microplate). After $24 \mathrm{~h}$ incubation at $4{ }^{\circ} \mathrm{C}$, the solution was removed, and the plates were blocked with $250 \mu \mathrm{L}$ of $4 \%(\mathrm{w} / \mathrm{v})$ nonfat milk (BioRad) in PBS $+0.5 \%$ (v/v) Tween-20 (PBST) for $1 \mathrm{~h}$ at room temperature. Then the wells were washed three times with PBST, and the pre-diluted blood sera or plasma in PBST with $1 \%$ $(\mathrm{w} / \mathrm{v})$ non-fat milk was added $(100 \mu \mathrm{L}$ per well). Following incubation at $37^{\circ} \mathrm{C}$ for $1 \mathrm{~h}$, the wells were washed six times with PBST. Next, 1:30,000 dilution of a goat anti-human IgG HRP-conjugate (Sigma-Aldrich, cat \#A8667) in PBST was added (100 $\mu \mathrm{L} /$ well). After incubation at $37^{\circ} \mathrm{C}$ for $40 \mathrm{~min}$, the wells were washed six times with PBST and a Liquid Substrate solution was added $(100 \mu \mathrm{L} /$ well $)$. The Liquid Substrate solution for one 96 plate was prepared by mixing $1 \mathrm{~mL}$ of $5 \mathrm{mM} \mathrm{TMB}$ $\left(3,3^{\prime}, 5,5^{\prime}\right.$-Tetramethylbenzidine) solution in $30 \%(\mathrm{v} / \mathrm{v})$ DMSO with $10 \mathrm{~mL}$ of $0.023 \% \mathrm{H}_{2} \mathrm{O}_{2}$ solution in $31 \mathrm{mM}$ 
citrate buffer $(\mathrm{pH}=4.0)$. After incubation for $5 \mathrm{~min}$ with Liquid Substrate solution, the reaction mixtures were quenched by $0.25 \mathrm{M} \mathrm{H}_{2} \mathrm{SO}_{4}(100 \mu \mathrm{L} /$ well). The signal was quantified by measurement of optical density at $450 \mathrm{~nm}\left(\mathrm{OD}_{450}\right)$ using Tecan Spark plate reader. The data were presented as a function of $\mathrm{OD}_{450}$ signal vs serum/plasma dilution factor, and the levels of RBDspecific IgG antibodies were expressed as titers (defined as the final dilutions of samples at which the signal is above the background).

\section{Expression and purification of recombinant ACE2-hFc and SUMOstar-ACE2 fusions}

The sequence encoding $\mathrm{N}$-terminal peptidase domain of human ACE2 (residues 18-615) was cloned into pAbVec vector in frame with a $\mathrm{C}$-terminal $\mathrm{Fc}$ tag of the human IgG1 (domains $\mathrm{CH} 1-\mathrm{CH} 3$ ). Also, a construct encoding His6-SUMOstar-ACE2 fusion (ACE2 residues 18-740) was obtained by standard cloning into the pM-SUMOstar mammalian expression vector (cat \#7121, LifeSensors). The expression constructs obtained were transiently transfected into HEK293T cells as described above. The supernatants were collected on day 7 post-transfection. Fc-tagged ACE2 protein was then purified with a Protein A column, whereas His6-SUMOstar-ACE2 fusion was purified on a Ni-NTA resin.

\section{Single B cell sorting}

PBMCs (peripheral blood mononuclear cells) were isolated from 9 to $18 \mathrm{~mL}$ venous blood by differential centrifugation over Ficoll Paque. Live B cells were identified by staining with DAPI, anti-human CD19-PE (Sorbent, Russia) and anti-human IgG-FITC (Sorbent, Russia) conjugates $(5 \mu \mathrm{L} / 1$ million PBMCs each). B cells were additionally stained with biotinylated recombinant SARSCoV-2 RBD $(2 \mu \mathrm{g} / \mathrm{mL})$ followed by detection with APClabeled streptavidin (Thermo Fisher Scientific). Target B cell population was gated as RBDhighCD19+IgG + DAPI $^{-}$. Individual RBD-specific B cells were single sorted into PCR tube strips pre-aliquoted with $10 \mu \mathrm{L} \mathrm{H}_{2} \mathrm{O}$ and $0.25 \mu \mathrm{L}$ RiboLock (Thermo Fisher Scientific) using Sony SH800 cell sorter (single-cell mode); the strips were kept frozen at $-70^{\circ} \mathrm{C}$.

Single-cell CDNA synthesis, reverse transcription PCR, and cloning of antibody sequences into expression vectors

All procedures were performed essentially as described $^{66}$, except that the protocol for $\mu$ gene amplification was used for $\gamma$ and $\lambda$ genes. Primer set reported by Tiller and colleagues ${ }^{67}$ was used for amplification of antibody

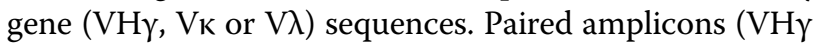
$+\mathrm{VK} / \mathrm{V} \lambda$ chains) were Sanger-sequenced and cloned into pAbVec series of vectors encoding constant regions of human $\gamma 1, \kappa$ or $\lambda$ chains, as described ${ }^{67}$.

\section{Antibody expression and purification}

HEK293T cells were used for antibody expression. Pairs of expression constructs encoding appropriate light and heavy chains were delivered into HEK293T cells using calcium phosphate transfection $^{68}$. Typically, $12 \mathrm{~h}$ before transfection 107 cells were plated on a $150 \mathrm{~cm}^{2}$ flask in IMDM (Gibco, Thermo Fisher Scientific) supplemented with 10\% FBS (Gibco, Thermo Fisher Scientific) and Penicillin/Streptomycin mix (Gibco, Thermo Fisher Scientific). Plasmid DNAs were pre-mixed in a 1:1 molar ratio, and $2 \mathrm{M} \mathrm{CaCl}_{2}$ was added to a final concentration of $25 \mathrm{mM}$. Volume of the transfection mixture was adjusted by adding sterile water to $3 \mathrm{~mL}$. The mixture was slowly added to $3 \mathrm{~mL} 2 \times$ HBS solution $(50 \mathrm{mM}$ HEPES, $1.5 \mathrm{mM} \mathrm{Na}_{2} \mathrm{HPO}_{4}, 280 \mathrm{mM} \mathrm{NaCl}, 10 \mathrm{mM} \mathrm{KCl}$, $12 \mathrm{mM}$ sucrose, $\mathrm{pH}=7.11$ ) under constant vortexing, and the resulting solution was added dropwise to the cells. $8 \mathrm{~h}$ later, growth medium was replaced with a serum-free EX-CELL® 293 Serum-Free Medium (Sigma). Transfected cells were kept for 6 days in a $\mathrm{CO}_{2}$ incubator at $37^{\circ} \mathrm{C}, 5 \% \mathrm{CO}_{2}$. Cell supernatants cleared of the cell debris by brief centrifugation $(4000 \times g, 10 \mathrm{~min})$ were filtered through a $0.22 \mu \mathrm{m}$ PES-filter (TPP), and antibodies were purified on Protein A agarose column (McLab, USA, \#PPA-503) according to the manufacturer's instructions. Briefly, after loading the column was washed twice with PBS. The antibodies were eluted with $0.1 \mathrm{M}$ glycine, $\mathrm{pH} 2.7,150 \mathrm{mM} \mathrm{NaCl}$, into the neutralization buffer of $1 \mathrm{M}$ Tris, $\mathrm{pH}$ 8.0, in a 1:10 ratio. Purity of antibodies was controlled by running a 15\% SDS-PAGE. Antibodies were then dialyzed overnight in PBS and concentrated using Ultra-15 Ultracel-100K (Amicon) to a final concentration of $2 \mathrm{mg} / \mathrm{mL}$.

\section{Cloning of wild-type (WT) and mutant Spike variants}

The construct pCAGGS-S carrying a codon-optimized cassette encoding a full-length SARS-CoV-2 $\mathrm{S}$ protein (reference Wuhan-Hu-1 isolate) was first modified to delete the sequence that corresponds to the $19 \mathrm{C}$-terminal residues of the $\mathrm{S}$ protein, which has been shown to boost the viral titers ${ }^{69}$. pCAGGS-S $\Delta 19$ plasmid was obtained. Next, sets of complementary mutagenic primers (27 nt each) centered at the desired site were used to introduce the individual mutations (E406W, K417N, N439K, K444Q, N460T, A475V, E484K, F486K, F490L, N501Y), double mutations (L452R + T478K, L452Q + F490S, $\mathrm{L} 452 \mathrm{R}+\mathrm{E} 484 \mathrm{Q})$ or a triple "KEN" mutation $(\mathrm{K} 417 \mathrm{~N}+$ $\mathrm{E} 484 \mathrm{~K}+\mathrm{N} 501 \mathrm{Y}$ ) into the coding sequence of $\mathrm{S} \Delta 19$. Sequence identity was confirmed by Sanger sequencing.

\section{FACS assay for antibody binding to Spike proteins expressed on the surface of HEK293T cells}

Antibodies were tested for how well they may recognize full-length SARS-CoV-2, HCoV-229E, and HCoV-NL63 S 
proteins expressed on the surface of HEK293T cells. Cells were transfected with appropriate plasmids 1-2 days before the assay, washed with PBS and incubated with antibodies at the final concentration of $3 \mu \mathrm{g} / \mathrm{mL}$ for $30 \mathrm{~min}$ at $4{ }^{\circ} \mathrm{C}$. After three times of washing with PBS, APC-conjugated donkey-anti-human IgG (1:600 dilution) (Jackson ImmunoResearch) was added and incubation proceeded for an additional $30 \mathrm{~min}$. To exclude dead cells, 7AAD (Sigma) was added to a final concentration of $0.5 \mu \mathrm{g} / \mathrm{mL}$. Cell suspensions were run on a BD FACS Canto II cytometer.

\section{FACS-based assay for competitive antibody binding to SARS-CoV-2 RBD (ACE2 blocking cell-based assay)}

Antibodies $(2 \mu \mathrm{g} / \mathrm{mL})$ were premixed with biotinylated SARS-CoV-2 RBD $(0.3 \mu \mathrm{g} / \mathrm{mL})$ in FACS staining buffer $(\mathrm{PBS}+1.5 \% \mathrm{FBS})$ and incubated for $15 \mathrm{~min}$ at room temperature. Antibody/RBD mixture was added to the suspension of 30,000 ACE2-HEK293T cells in the same buffer and incubation proceeded for $30 \mathrm{~min}$ at $4{ }^{\circ} \mathrm{C}$. Next, the cells were washed two times with FACS staining buffer and incubated with APC-conjugated streptavidin (1:600) (Thermo Fisher Scientific) in FACS staining buffer for $30 \mathrm{~min}$. BD FACSCantoII flow cytometer was used for fluorescence signal acquisition. Irrelevant antibodies were used as a control. Background fluorescence signal from ACE2-HEK293T cells stained with APC-streptavidin conjugate was used for gating.

\section{FACS-based autoreactivity assay}

Human HEp-2 cells were detached from the plastic using Versene solution, washed three times with PBS, and fixed with $2 \%$ paraformaldehyde for $10 \mathrm{~min}$ on ice. Saponin $(0.05 \%)$ was then added to permeabilize the cells. Primary antibodies specific for Actin (ab3280, Abcam) and BIP (ab21685, Abcam) were used as positive controls. All subsequent steps were done in FACS staining buffer supplemented with saponin. Specifically, cell suspensions were incubated with antibodies $(5 \mu \mathrm{g} / \mathrm{mL})$ for $30 \mathrm{~min}$, washed extensively, which was followed by the addition of APCconjugated donkey-anti-human IgG (1:600) (Jackson ImmunoResearch), goat-anti-rabbit-Alexa488 (1:600, Thermo Fisher Scientific), or goat-anti-mouse-Alexa488 (1:600, Thermo Fisher Scientific). Cells to which no primary antibody was added were used to determine the level of background fluorescence. Cell suspensions were then analyzed on BD FACS Canto II cytometer. Fold increase in autoreactivity was calculated using the following formula: MFI(antibody)-MFI(background control)/MFI(background control).

\section{Production of SARS-CoV-2 S-pseudotyped lentiviral particles}

HEK293T cells were transfected as above with a 4:6:3 molar mixture of plasmids psPAX2, pLV-EGFP, and a
pCAGGS-Spike $\Delta 19$ plasmid encoding either a WT or mutated variants of truncated SARS-CoV-2 $\mathrm{S}$ protein (S $\Delta 19)$. Eight hours after transfection, growth medium was replaced with Opti-Mem (Gibco, Thermo Fisher Scientific) supplemented with 2.5\% FBS (Gibco, Thermo Fisher Scientific). Two days later, supernatants were collected and pre-cleared by low-speed centrifugation. Next, pseudotyped lentiviral particles were concentrated by centrifugation at $20,000 \times g, 4{ }^{\circ} \mathrm{C}$ for $90 \mathrm{~min}$ and used in downstream assays.

\section{SARS-CoV-2 S-pseudotyped lentivirus neutralization assay}

ACE2-HEK293T cells stably expressing human ACE2 were seeded at a density of 30,000 cells/well in a 96-well plate on the day of neutralization assay. Antibodies were serially diluted in Opti-MEM $+2.5 \%$ FBS in twofold steps to concentrations ranging from $0.5 \mathrm{ng} / \mathrm{mL}$ to $1 \mu \mathrm{g} / \mathrm{mL}$ and co-incubated with 20,000 S-pseudotyped lentiviral particles for $30 \mathrm{~min}$ at $37^{\circ} \mathrm{C}$ in a volume of $100 \mu \mathrm{L}$. Twofold serum dilutions were prepared (range 1:80-1:2560) and processed similarly. Antibody (serum)/S-pseudotyped lentivirus mixture was added to ACE2-HEK293T cells and the plate was returned to $\mathrm{CO}_{2}$ incubator. $72 \mathrm{~h}$ following transduction, the percentage of transduced $\left(\mathrm{GFP}^{+}\right)$cells was measured in the cultures using flow cytometry. The half-maximal inhibitory concentration $\left(\mathrm{IC}_{50}\right)$ or inhibitory dilution $\left(\mathrm{ID}_{50}\right)$ was determined by non-linear regression as the concentration of antibody/serum dilution that neutralized $50 \%$ of the pseudotyped lentivirus. Data from two independent experiments were used.

\section{SARS-CoV-2 isolates}

Two distinct clinical isolates of SARS-CoV-2 were used in our work. hCoV-19/Russia/Moscow-PMVL-12/2020 (EPI_ISL_572398), which belongs to the B.1.1.4 lineage and carries three S mutations (D614G, S686del, and V687I) neither of which map to the RBD, as well as a single amino acid deletion in the S1/S2 cleavage loop, was used for in vitro neutralization assays. A second isolate, SARS-CoV-2/human/RUS/Nsk-FRCFTM-1/2020

(EPI_ISL_481284) characterized by a single D614G substitution in the $S$ protein (lineage B.1) was used for in vivo studies in hamsters.

\section{SARS-CoV-2 neutralization assay}

Microculture virus neutralization assay was performed as described by Nurtop and colleagues ${ }^{70}$ in 96 -well plates (Costar) using VeroE6 cells grown in DMEM $+5 \%$ FCS as the targets. FCS supplementation was reduced to $1 \%$ in the maintenance medium. Equal volume of serially diluted monoclonal antibodies were mixed with the viral supernatant $\left(100 \mathrm{TCID}_{50}(50 \%\right.$ Tissue Culture Infectious Dose) $/ 100 \mu \mathrm{L}$ ) and left at $37^{\circ} \mathrm{C}$ for $1 \mathrm{~h}$. Virus/antibody mixes $(100 \mu \mathrm{L})$ were then transferred into wells with a 
monolayer of VeroE6 cells. On days 5-7 post infection, wells were visually screened under an inverted microscope. $\mathrm{IC}_{100}$ was defined as the lowest concentration of antibody (or the highest dilution of the serum) that provided complete protection against $100 \mathrm{TCID}_{50}$ in $100 \mu \mathrm{L}$. Viral titers were verified for each experiment.

\section{Assessment of antibody concentration via BLI}

Concentration of purified antibodies or antibodies present in crude supernatants of transfected cells was measured on an OctetK2 instrument (ForteBio) using Protein A Calibrator Set (cat \#18-1031) and ProA biosensors (cat \#18-5010). Each antibody dilution was run in duplicate. Calibration curve was plotted based on 8 standard IgG concentrations $(1,3,10,30,100,300,500,700 \mu \mathrm{g} / \mathrm{mL})$ in at least two replicates.

\section{BLI measurements of $K D$, Kon, and Koff for purified antibodies}

Measurement of binding kinetics for antibody/ RBDHis6 was performed on Octet K2 instrument (ForteBio) using NTA biosensors (cat \#18-5101). RBD-His6 (30 $\mu \mathrm{g} /$ $\mathrm{mL}$ ) was immobilized on the sensor chip. Irrelevant $6 \times$ His-tagged Fn3 protein $(30 \mu \mathrm{g} / \mathrm{mL})$ of similar molecular weight was immobilized on the control sensor. Next, the proteins were irreversibly immobilized on the sensors via EDC/NHS coupling, according to the manufacturer's instructions. To characterize the $K \mathrm{D}$ values for the selected monoclonal antibodies and RBD-His6, singlepoint (26.7 nM concentration of RBD-His6 was chosen) measurements were done. Full Local Fitting, Bivalent model, $\mathrm{R} 2>0.9, \mathrm{X} 2<3$ was used for data processing. Nine leading antibody candidates (iB3, iB6, iB9, iB12, iB13, $i B 14, i B 15, i B 19$, and $i B 20)$ were subjected to a more detailed kinetic characterization using several concentration datapoints. For this purpose, we used AHC biosensors (cat \#18-5060) and immobilized the antibodies of interest or the control irrelevant HIV-specific antibody glVRC01 $(75 \mu \mathrm{g} / \mathrm{mL})$. Loaded sensors were run against a panel of six RBD concentrations $(6.25 \mathrm{nM}, 12.5 \mathrm{nM}$, $25 \mathrm{nM}$ и $50 \mathrm{nM}, 100 \mathrm{nM}, 200 \mathrm{nM})$. Data processing was based on the Full Global Fitting, Bivalent model, R2 $>0.9$, $\mathrm{X} 2<3$ as well as following steps: Baseline $30 \mathrm{~s}$, Loading $300 \mathrm{~s}$, Baseline2 $60 \mathrm{~s}$, Association $600 \mathrm{~s}$, Dissociation $1500 \mathrm{~s}$, Regeneration $3 \times 5 \mathrm{~s}$.

\section{Epitope binning (competition assay) via BLI}

NTA biosensors (cat \#18-5101) were used for epitope binning. $14 \mu \mathrm{g} / \mathrm{mL}$ RBD-His6 was loaded on the sensor. $\mathrm{Ab} 1$ and $\mathrm{Ab} 2$ were added at $75 \mu \mathrm{g} / \mathrm{mL}(500 \mathrm{nM})$ concentration. The following 6-step scheme was used: Baseline $60 \mathrm{~s}$, Loading $200 \mathrm{~s}$, Baseline $230 \mathrm{~s}$, Saturation Ab1 600 s, Competing Ab2 600 s, Regeneration in Glycine$\mathrm{HCl}, \mathrm{pH} 1.7,5 \times 3 \mathrm{~s}$.

\section{In vivo protection assay in hamster model}

Female Syrian hamsters housed in the SPF animal facility of the Institute of Cytology and Genetics SB RAS (Novosibirsk) were purchased for animal studies. Animals were weighted and the values ranged from 75.5 to $108.5 \mathrm{~g}$. In the prophylactic scheme, seven groups of animals $(n=$ 6 each) were intraperitoneally (i/p) administered with $10 \mathrm{mg} / \mathrm{kg}$ iB12 (group 1), $1 \mathrm{mg} / \mathrm{kg}$ iB12 (group 2), $10 \mathrm{mg} /$ $\mathrm{kg}$ 1:1 mixture of iB6 and iB20 (group 3), $1 \mathrm{mg} / \mathrm{kg}$ mix of iB6 and iB20 (group 4), $10 \mathrm{mg} / \mathrm{kg}$ total human IgG (group 5 , negative control) $24 \mathrm{~h}$ before infection ( $-1 \mathrm{dpi})$. Untreated animals (group 6) were used as an additional baseline control. Next day, (0 dpi) SARS-CoV-2 was given intranasally $\left(50 \mu \mathrm{L} /\right.$ nostril) at a total dose of $1.3 \times 10^{3}$ plaque-forming units. In the therapeutic regimen, six hamsters were infected as above and administered iB12 $(10 \mathrm{mg} / \mathrm{kg}, \mathrm{i} / \mathrm{p}) 6 \mathrm{~h}$ post-infection (group 7). Animals were monitored for any signs of distress and weighed daily. In each group, three animals were euthanized on 5 dpi. Lungs were extracted for quantification of viral load and pathology analysis; blood samples were collected to measure the levels of human IgGs in the serum. Experiment to address the protective activity of iB14 nAb was similar by design, but included extended groups (6-7 animals) and an additional therapeutic timepoint at $24 \mathrm{~h}$.

\section{ELISA of human IgG levels in hamster sera}

Levels of injected human IgG antibodies in the sera of infected hamsters were assessed by ELISA. 96-well microtiter plates (Greiner Bio-One) were pre-coated with $2 \mu \mathrm{g} / \mathrm{mL}$ of mouse anti-human IgG monoclonal antibodies overnight at $4{ }^{\circ} \mathrm{C}$. After blocking with $2 \%$ milk in PBS, hamster sera diluted as 1:200 (animal groups 1, 3, 5,7 ) or 1:20 (groups $2,4,6$ ) were added to the wells and incubated for $1 \mathrm{~h}$ at room temperature. The plates were then washed five times with PBST and mouse monoclonal anti-human IgG-HRP $(1: 12,000)$ was added. After incubation for $1 \mathrm{~h}$ at room temperature, the plates were washed and developed with TMB substrate. The reaction was stopped by the addition of $0.5 \mathrm{M} \mathrm{H}_{2} \mathrm{SO}_{4}$ and $\mathrm{OD}_{450}$ was measured on Multiskan FC (Thermo Scientific) plate reader.

For the iB14 efficacy in vivo experiment, hamster sera were processed as above. Dilutions of 1:200 and 1:20 were used for animals injected with $10 \mathrm{mg} / \mathrm{kg}$ and $1 \mathrm{mg} / \mathrm{kg}$ iB14 (or control total human IgG), respectively.

\section{Assessment of viral load by RT-qPCR}

Half of the left lobe of the hamster lung was weighted, placed into LIRA solution (Biolabmix) and frozen. The samples were then thoroughly homogenized and RNA was isolated according to instructions of the manufacturer. RevertAid cDNA synthesis kit (Thermo Scientific) was used to convert $1 \mathrm{mg}$ total RNA into cDNA 
(random hexamers were used). RT-qPCR using a 1:10 dilution of cDNA as a template was set up. Two sets of primers specific for SARS-CoV-2 $R d R p$ and $E$ genes have been described ${ }^{71}$, and are known to quantify the levels of genomic or genomic+subgenomic RNAs in the sample. Primers detecting hamster Rpl18 transcripts ${ }^{72}$ were used for inter-sample normalization. Standard curve obtained by spiking total hamster lung cDNA with the known copy number of plasmid encoding $\mathrm{E}$, was used to establish the minimum detection threshold of the assay as well as to convert the $\Delta \mathrm{Ct}$ values into copies of the virus. Each assay was performed in triplicate with two technical replicates, and each assay included no-template negative controls.

\section{Hamster lung histopathology grading}

Paraffin-embedded lung sections were stained with haematoxylin and eosin (H\&E) and analyzed by a trained histologist (MAG) who was masked as to the sample origin. Lung injury severity scores were assigned as follows. Normal: lung structure is nearly identical to that of the control, non-infected animals. Mild: features of mild interstitial pneumonia, lumena of alveoli are narrowed, singular perivascular swellings, alveolar septae are visually thickened. Moderate: pronounced desquamation of the epithelial lining and perivascular swellings of large vessels. Severe: advanced interstitial pneumonia, multiple interstitial swellings, lung structure damaged, large areas of atelectasis and emphysema, necrotic foci, leukocytic infiltration, multiple haemorrhages.

\section{Statistical analyses}

Statistical analysis of the significance of differences between groups was performed in GraphPad Prism 6: ordinary one-way ANOVA (multiple comparisons) for the viral load analysis (Fig. 6b), and two-way ANOVA for the weight change analysis (Fig. 6a).

\section{Acknowledgements}

The authors gratefully acknowledge the resources provided by the "Molecular and Cellular Biology" core facility of the IMCB SB RAS, as well as S7 Airlines for their prompt logistics support. We are thankful to our patients, colleagues and friends for their support of the study. A.V.T. was supported by the Russian Fund of Basic Research (RFBR) grant No. 20-04-60527. Development of the modified protocol for single B cell sorting was supported by the RFBR grant No. 18-2908051 (A.A.G.) and by the Basic scientific research program project No. 02462021-0016 (A.V.T.). ELISA experiments were funded by the Russian Ministry of Science and Higher Education of the Russian Federation (agreement 075-152019-1660).

\footnotetext{
Author details

'Institute of Molecular and Cellular Biology, Siberian Branch of the Russian Academy of Sciences, Novosibirsk, Russia. ${ }^{2}$ Novosibirsk State University, Novosibirsk, Russia. ${ }^{3}$ National Research Center of Epidemiology and Microbiology named after the honorary academician N.F. Gamaleya of the Ministry of Health of the Russian Federation, Moscow, Russia. ${ }^{4}$ Federal Research Center of Fundamental and Translational Medicine, Novosibirsk, Russia. ${ }^{5}$ Dagestan State University, Makhachkala, Republic of Dagestan, Russia. ${ }^{6}$ Federal Research and Clinical Center for Specialized Medical Care, FMBA of Russia, Moscow, Russia. ${ }^{7}$ Center for Precision Genome Editing and Genetic
}

Technologies for Biomedicine, Engelhardt Institute of Molecular Biology, Russian Academy of Sciences, Moscow, Russia

\section{Author contributions}

Conceived and designed the experiments: K.O.B., S.V.K., S.V.G., A.A.G., V.F.L., A.V. I., V.P.B., and A.V.T. Performed the experiments: K.O.B., S.V.K., T.N.B., S.V.G., A.A.G. O.Y.V., N.A.C., A.N.C., L.V.M., A.M.N., P.P.S., V.T.V.-E., V.F.L., A.M.S., A.Y.A., A.G.M., Y.V.K., and M.A.G. Analyzed the data: K.O.B., S.V.K., T.N.B., S.V.G., A.A.G., L.V.M., and A.V.T. Contributed reagents/materials: G.M.Y. and T.V.K. Wrote the manuscript: S.V.K., S.V.G., A.A.G., and A.V.T. All authors read and approved the final manuscript.

\section{Conflict of interest}

Patent applications are being filed for the iB series of nAbs. K.O.B., L.V.M., O.Y.V. A.M.N., N.A.C., and A.V.T. are employees of IMGEN+, LLC. This work was funded by IMGEN+, LLC and several grants listed above.

\section{Ethics statement}

This study adhered to the human experimentation guidelines as outlined by the Helsinki Declaration of 1975. The collection and analysis of clinical information and biological samples was approved by the Ethics Committee at the FRSC FMBA of Russia, protocol NO. 4_2020 dated April 28, 2020, which also approved all the procedures for obtaining written informed consent from all participants in the study. Two copies of the consent were signed, with one copy provided to the participants and one copy archived at the Federal Research Clinical Center of the Federal Biomedical Agency of Russia (FRCC FMBA of Russia, Moscow). This study was also conducted in accordance with the recommendations of the Animal Research Guidelines of the Committee on Biomedical Ethics of the Federal Research Center for Fundamental and Translational Medicine (Novosibirsk, Russia) and approved by the Committee, protocol no 35 on December 5, 2020.

\section{Publisher's note}

Springer Nature remains neutral with regard to jurisdictional claims in published maps and institutional affiliations.

Supplementary information The online version contains supplementary material available at https://doi.org/10.1038/s41421-021-00340-8.

Received: 16 April 2021 Accepted: 24 September 2021

Published online: 19 October 2021

References

1. Voysey, M. et al. Safety and efficacy of the ChAdOx1 nCoV-19 vaccine (AZD1222) against SARS-CoV-2: an interim analysis of four randomised controlled trials in Brazil, South Africa, and the UK. Lancet 397, 99-111 (2021).

2. Logunov, D. Y. et al. Safety and efficacy of an rAd26 and rAd5 vector-based heterologous prime-boost COVID-19 vaccine: an interim analysis of a randomised controlled phase 3 trial in Russia. Lancet 397, 671-681 (2021).

3. Polack, F. P. et al. Safety and efficacy of the BNT162b2 mRNA Covid-19 Vaccine. N. Engl. J. Med. 383, 2603-2615 (2020).

4. Baden, L. R. et al. Efficacy and safety of the mRNA-1273 SARS-CoV-2 Vaccine. N. Engl. J. Med. 384, 403-416 (2021).

5. Brouwer, P. J. M. et al. Potent neutralizing antibodies from COVID-19 patients define multiple targets of vulnerability. Science 369, 643-650 (2020).

6. Wu, Y. et al. A noncompeting pair of human neutralizing antibodies block COVID-19 virus binding to its receptor ACE2. Science 368, 1274-1278 (2020).

7. Jones, B. E. et al. The neutralizing antibody, LY-CoV555, protects against SARS-CoV-2 infection in nonhuman primates. Sci. Transl. Med. 13, eabf1906 (2021).

8. Hansen, J. et al. Studies in humanized mice and convalescent humans yield a SARS-CoV-2 antibody cocktail. Science 369, 1010-1014 (2020).

9. Wang, C. et al. A human monoclonal antibody blocking SARS-CoV-2 infection. Nat. Commun. 11, 2251 (2020).

10. Seydoux, E. et al. Analysis of a SARS-CoV-2-infected individual reveals development of potent neutralizing antibodies with limited somatic mutation. Immunity 53, 98-105.e5 (2020). 
11. Zost, S. J. et al. Rapid isolation and profiling of a diverse panel of human monoclonal antibodies targeting the SARS-CoV-2 spike protein. Nat. Med. $\mathbf{2 6}$ 1422-1427 (2020).

12. Rogers, T. F. et al. Isolation of potent SARS-CoV-2 neutralizing antibodies and protection from disease in a small animal model. Science 369, 956-963 (2020).

13. Shi, R. et al. A human neutralizing antibody targets the receptor-binding site of SARS-CoV-2. Nature 584, 120-124 (2020).

14. Ju, B. et al. Human neutralizing antibodies elicited by SARS-CoV-2 infection Nature 584, 115-119 (2020).

15. Robbiani, D. F. et al. Convergent antibody responses to SARS-CoV-2 in convalescent individuals. Nature 584, 437-442 (2020).

16. Liu, L. et al. Potent neutralizing antibodies against multiple epitopes on SARSCoV-2 spike. Nature 584, 450-456 (2020).

17. Chi, X. et al. A neutralizing human antibody binds to the $\mathrm{N}$-terminal domain of the Spike protein of SARS-CoV-2. Science 369, 650-655 (2020).

18. Wan, J. et al. Human-lgG-neutralizing monoclonal antibodies block the SARSCoV-2 infection. Cell Rep. 32, 107918 (2020).

19. Kreer, C. et al. Longitudinal isolation of potent near-germline SARS-CoV-2neutralizing antibodies from COVID-19 patients. Cell 182, 843-854.e12 (2020).

20. Kreye, J. et al. A therapeutic non-self-reactive SARS-CoV-2 antibody protects from lung pathology in a COVID-19 hamster model. Cell 183, 1058-1069.e19 (2020).

21. McCallum, M. et al. N-terminal domain antigenic mapping reveals a site of vulnerability for SARS-CoV-2. Cell 184, 2332-2347.e16 (2021).

22. Chen, X. et al. Human monoclonal antibodies block the binding of SARS-CoV2 spike protein to angiotensin converting enzyme 2 receptor. Cell. Mol. Immunol. 17, 647-649 (2020).

23. Cao, Y. et al. Potent neutralizing antibodies against SARS-CoV-2 identified by high-throughput single-cell sequencing of convalescent patients' B cells. Cell 182, 73-84.e16 (2020).

24. Andreano, E. et al. Identification of neutralizing human monoclonal antibodies from Italian Covid-19 convalescent patients. bioRxiv https://doi.org/10.1101/ 2020.05.05.078154 (2020).

25. Wec, A. Z. et al. Broad sarbecovirus neutralizing antibodies define a key site of vulnerability on the SARS-CoV-2 spike protein. bioRxiv https://doi.org/10.1101/ 2020.05.15.096511 (2020).

26. Tian, $X$. et al. Potent binding of 2019 novel coronavirus spike protein by a SARS coronavirus-specific human monoclonal antibody. Emerg. Microbes Infect. 9 , 382-385 (2020).

27. Pinto, D. et al. Cross-neutralization of SARS-CoV-2 by a human monoclonal SARS-CoV antibody. Nature 583, 290-295 (2020).

28. Li, W. et al. Rapid identification of a human antibody with high prophylactic and therapeutic efficacy in three animal models of SARS-CoV-2 infection. Proc. Natl. Acad. Sci. USA 117, 29832-29838 (2020).

29. Parray, H. A. et al. Identification of an anti-SARS-CoV-2 receptor-binding domain-directed human monoclonal antibody from a naive semisynthetic library. J. Biol. Chem. 295, 12814-12821 (2020).

30. Wang, B. et al. Bivalent binding of a fully human lgG to the SARS-CoV-2 spike proteins reveals mechanisms of potent neutralization. bioRxiv https:/doi.org/ 10.1101/2020.07.14.203414 (2020).

31. $\mathrm{Wu}, \mathrm{Y}$. et al. Identification of Human Single-Domain Antibodies against SARSCoV-2. Cell Host Microbe 27, 891-898.e5 (2020).

32. $\mathrm{Ku}, \mathrm{Z}$. et al. Molecular determinants and mechanism for antibody cocktail preventing SARS-CoV-2 escape. Nat. Commun. 12, 469 (2021).

33. Fagre, A. C. et al. A potent SARS-CoV-2 neutralizing human monoclonal antibody that reduces viral burden and disease severity in Syrian hamsters. Front. Immunol. 11, 614256 (2020).

34. Noy-Porat, T. et al. A panel of human neutralizing mAbs targeting SARS-CoV-2 spike at multiple epitopes. Nat. Commun. 11, 4303 (2020).

35. Yao, $\mathrm{H}$. et al. Rational development of a human antibody cocktail that deploys multiple functions to confer Pan-SARS-CoVs protection. Cell Res. 31, 25-36 (2021).

36. Kim, C. et al. A therapeutic neutralizing antibody targeting receptor binding domain of SARS-CoV-2 spike protein. Nat. Commun. 12, 288 (2021).

37. Jiang, S., Zhang, X., Yang, Y., Hotez, P. J. \& Du, L. Neutralizing antibodies for the treatment of COVID-19. Nat. Biomed. Eng. 4, 1134-1139 (2020).

38. Rappazzo, C. G. et al. Broad and potent activity against SARS-like viruses by an engineered human monoclonal antibody. Science 371, 823-829 (2021).
39. Wec, A. Z. et al. Broad neutralization of SARS-related viruses by human monoclonal antibodies. Science 369, 731-736 (2020)

40. Planas, D. et al. Reduced sensitivity of SARS-CoV-2 variant Delta to antibody neutralization. Nature 596, 276-280 (2021).

41. Wang, P. et al. Antibody resistance of SARS-CoV-2 variants B.1.351 and B.1.1.7. Nature 593, 130-135 (2021).

42. Cathcart, A. L. et al. The dual function monoclonal antibodies VIR-7831 and VIR-7832 demonstrate potent in vitro and in vivo activity against SARS-CoV-2. bioRxiv https://doi.org/10.1101/2021.03.09.434607 (2021).

43. Ryu, D.-K. et al. Therapeutic effect of CT-P59 against SARS-CoV-2 South African variant. Biochem. Biophys. Res. Commun. 566, 135-140 (2021).

44. Prévost, J. et al. Cross-sectional evaluation of humoral responses against SARS CoV-2 spike. Cell Rep. Med. 1, 100126 (2020).

45. Wang, P. et al. SARS-CoV-2 neutralizing antibody responses are more robust in patients with severe disease. Emerg. Microbes Infect. 9, 2091-2093 (2020).

46. Garcia-Beltran, W. F. et al. COVID-19-neutralizing antibodies predict disease severity and survival. Cell 184, 476-488.e11 (2021).

47. Zost, S. J. et al. Potently neutralizing and protective human antibodies against SARS-CoV-2. Nature 584, 443-449 (2020).

48. Yuan, M., Liu, H., Wu, N. C. \& Wilson, I. A. Recognition of the SARS-CoV-2 receptor binding domain by neutralizing antibodies. Biochem. Biophys. Res. Commun. 538, 192-203 (2021).

49. Barnes, C. O. et al. Structures of human antibodies bound to SARS-CoV-2 spike reveal common epitopes and recurrent features of antibodies. Cell $\mathbf{1 8 2}$ 828-842.e16 (2020).

50. Barnes, C. O. et al. SARS-CoV-2 neutralizing antibody structures inform therapeutic strategies. Nature 588, 682-687 (2020).

51. Tortorici, M. A. et al. Ultrapotent human antibodies protect against SARS-CoV-2 challenge via multiple mechanisms. Science 370, 950-957 (2020).

52. Schmitz, A. J. et al. A public vaccine-induced human antibody protects against SARS-CoV-2 and emerging variants. bioRxiv https://doi.org/ 10.1101/2021.03.24.436864 (2021).

53. Weisblum, Y. et al. Escape from neutralizing antibodies by SARS-CoV-2 spike protein variants. elife 9, e61312 (2020).

54. Starr, T. N. et al. Prospective mapping of viral mutations that escape antibodies used to treat COVID-19. Science 371, 850-854 (2021).

55. Baum, A. et al. Antibody cocktail to SARS-CoV-2 spike protein prevents rapid mutational escape seen with individual antibodies. Science 369, 1014-1018 (2020).

56. Greaney, A. J. et al. Complete mapping of mutations to the SARS-CoV-2 spike receptor-binding domain that escape antibody recognition. Cell Host Microbe 29, 44-57.e9 (2021)

57. Shen, X. et al. SARS-CoV-2 variant B.1.1.7 is susceptible to neutralizing antibodies elicited by ancestral Spike vaccines. Cell Host Microbe. 29, 529-539.e3 (2021).

58. Du, S. et al. Structurally resolved SARS-CoV-2 antibody shows high efficacy in severely infected hamsters and provides a potent cocktail pairing strategy. Cell 183, 1013-1023.e13 (2020).

59. Wang, P. et al. Increased resistance of SARS-CoV-2 variants B.1.351 and B.1.1.7 to antibody neutralization. bioRxiv https://doi.org/10.1101/2021.01.25.428137 (2021).

60. Muik, A. et al. Neutralization of SARS-CoV-2 lineage B.1.1.7 pseudovirus by BNT162b2 vaccine-elicited human sera. Science 371, 1152-1153 (2021).

61. Xie, X. et al. Neutralization of SARS-CoV-2 spike 69/70 deletion, E484K and N501Y variants by BNT162b2 vaccine-elicited sera. Nat. Med. https://doi.org/ 10.1038/s41591-021-01270-4 (2021).

62. Wibmer, C. K. et al. SARS-CoV-2 501Y.V2 escapes neutralization by South African COVID-19 donor plasma. Nat Med. 27, 622-625 (2021).

63. Starr, T. N., Greaney, A. J., Dingens, A. S. \& Bloom, J. D. Complete map of SARSCoV-2 RBD mutations that escape the monoclonal antibody LY-CoV555 and its cocktail with LY-CoV016. bioRxiv https://doi.org/10.1101/2021.02.17.431683 (2021).

64. Padmanabhan, P., Desikan, R. \& Dixit, N. M. The quantitative landscape of the neutralizing antibody response to SARS-CoV-2. medRxiv https://doi.org/ 10.1101/2020.09.25.20201996 (2020)

65. Amanat, F. et al. A serological assay to detect SARS-CoV-2 seroconversion in humans. Nat. Med. 26, 1033-1036 (2020).

66. Guselnikov, S. V., Belovezhets, T. N., Kulemzin, S. V., Gorchakov, A. A. \& Taranin, A. $V$. A simple way to increase recovery of the expressed $\mathrm{VH}$ and $\mathrm{VL}$ genes in single-sorted human B cells. BioTechniques 67, 184-187 (2019). 
67. Tiller, $T$. et al. Efficient generation of monoclonal antibodies from single human B cells by single cell RT-PCR and expression vector cloning. J. Immunol. Methods 329, 112-124 (2008).

68. Chenuet, $\mathrm{S}$. et al. Calcium phosphate transfection generates mammalian recombinant cell lines with higher specific productivity than polyfection. Biotechnol. Bioeng. 101, 937-945 (2008).

69. Johnson, M. C. et al. Optimized pseudotyping conditions for the SARS-COV-2 spike glycoprotein. J. Virol. 94, e01062-20 (2020).
70. Nurtop, E. et al. Combination of ELISA screening and seroneutralisation tests to expedite Zika virus seroprevalence studies. Virol. J. 15, 192 (2018).

71. Corman, V. M. et al. Detection of 2019 novel coronavirus (2019-nCoV) by realtime RT-PCR. Euro Surveill. 25, 2000045 (2020).

72. Zivcec, M., Safronetz, D., Haddock, E., Feldmann, H. \& Ebihara, H. Validation of assays to monitor immune responses in the Syrian golden hamster (Mesocricetus auratus). J. Immunol. Methods 368, 24-35 (2011). 